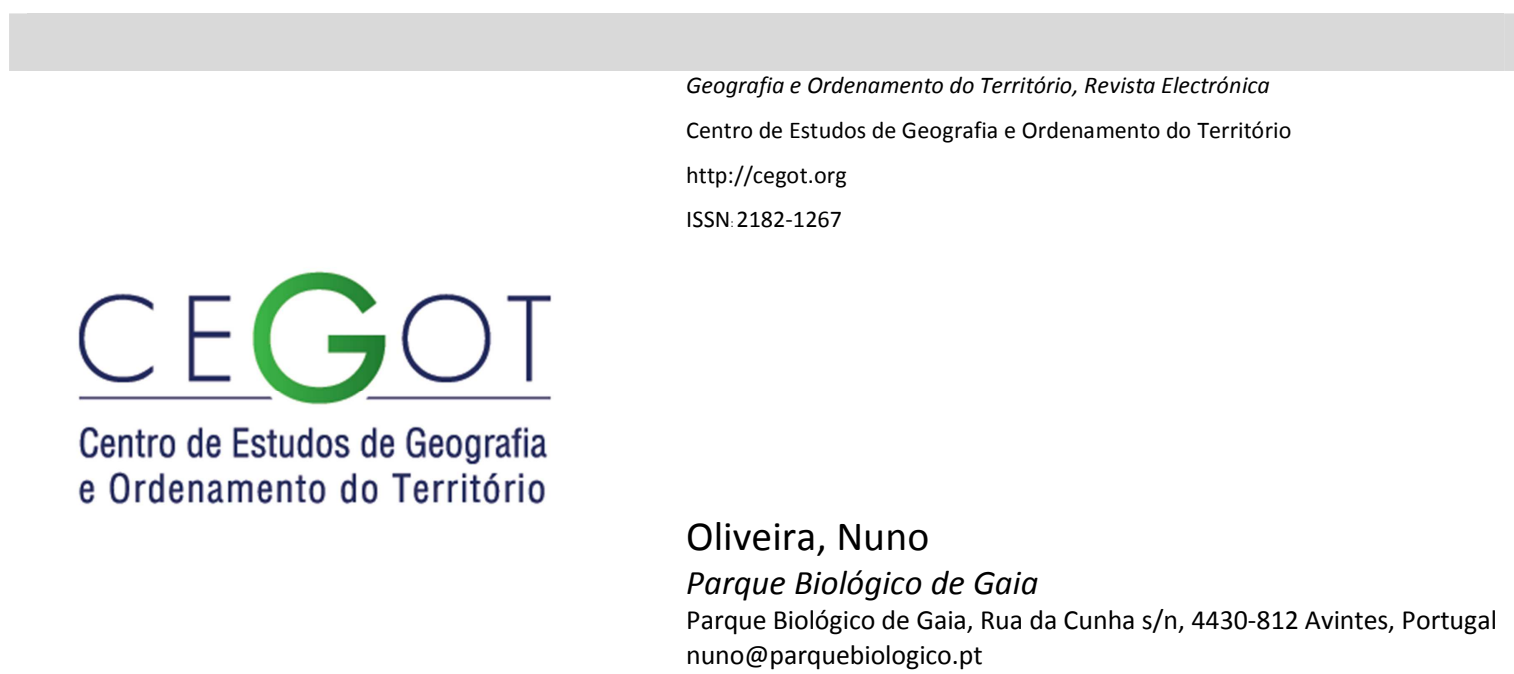

nuno@parquebiologico.pt

\title{
Alfred Smith (1822-1898), pioneiro do turismo ornitológico em Portugal
}

Referência: Oliveira, Nuno (2015). Alfred Smith (1822-1898), pioneiro do turismo ornitológico em Portugal. (GOT), n.o 7 (junho). Centro de Estudos de Geografia e Ordenamento do Território, p. 271-282, dx.doi.org/10.17127/got/2015.7.012

\section{Resumo}

Desde cedo Portugal foi um destino de turismo ornitológico (ecoturístico) e Alfred Smith foi um dos primeiros, senão o primeiro, turista a vir a Portugal, em 1868, motivado pelo interesse pelas aves. O livro que publicou contém uma lista inédita de aves de Portugal, que só encontrámos porque o bibliotecário da Academia de Ciências de Nova York acrescentou ao título, na ficha bibliográfica "com uma capítulo sobre as aves de Portugal, e uma lista de 235 espécies cuidadosamente determinadas". Hoje o turismo ornitológico e o ecoturismo já se estão a desenvolver a bom ritmo e as espécies de aves ibéricas (a par da paisagem, da flora e da restante fauna) constituem um produto turístico em que se deve apostar e que valoriza, essencialmente, as regiões do interior.

Palavras-Chave: Turismo ornitológico, birdwatching, ornitologia, aves ibéricas, regiões do interior, ecoturismo.

Abstract: Early Portugal was an ornithological tourism destination (ecotourism) and Alfred Smith was one of the first, if not the first, tourist to come to Portugal in 1868, motivated by interest in the birds. The book he published contains an unprecedented list of birds of Portugal, who only found because the librarian of the New York Academy of Sciences add to the title, the bibliographic record "with a chapter on the birds of Portugal, and a list of 235 species carefully determined". Today the ornithological tourism and ecotourism already are 
developing at a good rate and the species of Iberian birds (together with the landscape, flora and fauna) are a tourism product in which to invest and that values essentially the interior regions.

Keywords: Ornithological tourism, birdwatching, Iberian birds, interior regions, ecotourism.

\section{Introdução}

A variedade de aves em Portugal resulta da presença de duas regiões biogeográficas, a Atlântica e a Mediterrânica sendo, particularmente a segunda, a causa de presença de muitas espécies ausentes do Centro e Norte da Europa, o que sempre conferiu a Portugal um potencial de atração de estudiosos e observadores de aves; o mesmo se aplica à flora e à restante fauna.

Alfred Smith foi, provavelmente, a primeira pessoa a fazer turismo ornitológico em Portugal, quando nos visitou em abril e maio de 1868. Esta visita deu lugar a um artigo na conceituada revista inglesa de ornitologia Ibis, em 1868 (A Sketch of the Birds of Portugal) e a um livro descritivo da viagem, em 1870 (Narrative of a spring tour in Portugal).

O livro que publicou contém uma lista comentada de aves de Portugal, até agora desconhecida da comunidade ornitológica portuguesa, que só encontrámos porque o bibliotecário da Academia de Ciências de Nova York acrescentou ao título, na ficha bibliográfica "com uma capítulo sobre as aves de Portugal, e uma lista de 235 espécies cuidadosamente determinadas".

O pastor protestante Alfred Charles Smith (1822-1898) era um dos, então, quarenta membros honorários da prestigiada "British Otnitologists'Union". Foi reitor da igreja de Todos os Santos, em Yatesbury, Wiltshire, em Inglaterra, de 1852 a c. 1878 (vendeu este título em $1882^{1}$ ); foi, ainda, um amador da história natural, arqueologia e viagens, que se correspondeu com Charles Darwin ${ }^{2}$.

\footnotetext{
${ }^{1}$ Este título, em inglês "advowson" ou "patronage" era um direito da lei inglesa.

${ }^{2}$ Darwin Correspondence Project, http://www.darwinproject.ac.uk/all-darwins-correspondents
} 
Veio a Portugal com o pai, “... tal como nas melhores viagens dos últimos anos" e “...carregava uma espingarda, um par de binóculos, e todos os utensílios necessários a um ornitologista, parar obter e preservar espécimes de aves, ele [o pai] levou a sua câmara, e tudo o que um fotógrafo precisa." Para esta viagem Smith calculou gastar cerca de 50 libras.

Embarcou nas docas de Southampton no navio brasileiro Shannon por volta do dia de Páscoa de 1868. Visitou Lisboa, Sintra, Évora e Setúbal, e depois veio para o Norte, por Alcobaça, Batalha e Coimbra até ao Porto, de onde partiu para Braga e Viana.

Smith usou o comboio expresso de Coimbra para o Porto, e nisso gastou três horas; na parte final desta viagem, após passar Ovar, anota que “... agora surgiu a costa, com o extenso Atlântico a oeste, e areia nos dois lados, e nada mais que areia, pura e simples, para ser visto. Isto foi no final da nossa jornada, e depressa chegamos ao términos em Vila Nova de Gaia." Esta descrição faz sentido pois o revestimento florestal das dunas de Ovar, Cortegaça e Esmoriz iniciou-se, apenas, em 1930 (Lamy \& Rodrigues, 2000), pelo que à data da viagem de Smith (1868, recorde-se) a linha da caminho de ferro de Ovar a Vila Nova de Gaia atravessava os areais costeiros, com uma paisagem idêntica à que hoje ainda podemos ver um pouco no troço de S. Félix da Marinha.

Smith atravessou para o Porto pela Ponte Pênsil e instalou-se no Hotel Mary Castro que, nesta data, ainda seria na esquina da Rua de Sampaio Bruno com a do Bonjardim e, mais tarde, se mudou para a Rua das Motas, na Foz.

Entre o muito que visitaram e os impressionou no Porto cabe destacar os jardins do capelão da Feitoria inglesa, rev. Edward Whiteley, que, entre outras espécies, tinha um Tulipeiro (Liriodendron tulipifera), com cerca de 5,2 m de perímetro a $90 \mathrm{~cm}$ do solo, segundo as medições de Smith e do pai; atribuíram este excecional crescimento ao facto de ter um sistema de rega. Dizem que, no entanto, uma magnólia ali existente ainda era mais espetacular, com $18 \mathrm{~m}$ de altura. Também as camélias de diversas variedades chamaram a atenção de Smith.

O rev. Whiteley tinha um colégio na Rua de Entre-Quintas (Gonçalves, 2001), perto do Palácio de Cristal, onde fica a conhecida Casa Tait; esta propriedade, anteriormente designada Quinta de Meio, foi adquirida em 22/04/1900 pelo negociante inglês William Tait. 
O jardim do rev. Whiteley deveria ser o mesmo da futura Casa Tait, como comprova o majestoso Tulipeiro (Liriodendron tulipifera), ainda hoje existente.

\section{Aves de Portugal}

Na sua listagem de aves de Portugal, Alfred Smith começa por dizer que, à época, sobre as aves de Portugal apenas existia uma listagem em português feita pelo Professor Barbosa du Bocage $^{3}$, em 1862 e umas notas do George Frazer Mathews, que foram publicadas na revista "The Naturalist", do ano de 1864.

Quanto ao trabalho do Professor Barbosa du Bocage, Smith refere-se à brochura publicada em 1862 "Instruções praticas sobre o modo de coligir e remeter productos zoológicos para o Museu de Lisboa" que inclui uma lista comentada de 326 espécies de aves que ocorriam ou podiam ocorrer em Portugal, das quais Bocage apenas pôde confirmar a ocorrência de 280, das 440 que se conhecem hoje ${ }^{4}$. Curiosamente, entre as espécies cuja presença não conseguiu confirmar, estão algumas que hoje são comuns, como a Garça-branca-pequena (Egretta garzetta) ou a Gaivota-parda (Larus canus).

Por outro lado, a lista de Bocage de 1862 incluiu espécies cuja ocorrência em Portugal é duvidosa, como a Perdiz-mourisca (Alectoris barbara) (Fig. 1) de que só há três referências para o nosso país; um exemplar que Tait (1924) diz ter um tio seu caçado anos antes em Vendas Novas e duas que António Themido (1944) diz integrarem a coleção do rei D. Carlos e terem sido capturadas em Vila Viçosa em 20 e 24/12/1906. É uma espécie do Norte de África e na Península Ibérica a única população conhecida é em Gibraltar, embora haja alguns exemplares capturados em Telleria (Cádiz), na primeira metade do século XX (Lorenzo et al., 2003). Alguns sítios na internet referem a introdução recente em Portugal, para fins cinegéticos, o que não se conseguiu comprovar e, a ser verdade, é proibido.

\footnotetext{
${ }^{3}$ José Vicente Barbosa du Bocage (1823 -1907) foi um zoólogo e político português, Diretor do Museu de História Natural de Lisboa. Era primo em segundo grau do poeta Manuel Maria Barbosa du Bocage (17651805)

${ }^{4}$ Fonte: http://www.avesdeportugal.info/avesdeportugal.html, acedido em 7/7/2013.
} 
Quando, acima, Alfred Smith fala de G. F. Matews está a referir-se ao naturalista e arqueólogo que era vigário da Igreja de S. Pedro, em Mancetter (Warwickshire, UK), secretário do Club de Cricket de Hayles (Kent, UK) e do Clifton Rugby Football Club (Bristol, UK) que publicou em 1865 na revista inglesa "The Naturalist" o artigo "Notes on the Azurewinged magpie (Pica cyanea), \&c." (TA: Notas sobre a Pega-azul (Cyanopica cyanea), etc.); o autor acrescentou ao título "etc." porque fala de diversas outras espécies de aves que viu nos arredores de Lisboa, ao todo três dezenas de espécies, quando cá esteve em fevereiro de 1863 e em janeiro de 1865, e no Funchal, em dezembro de 1863.

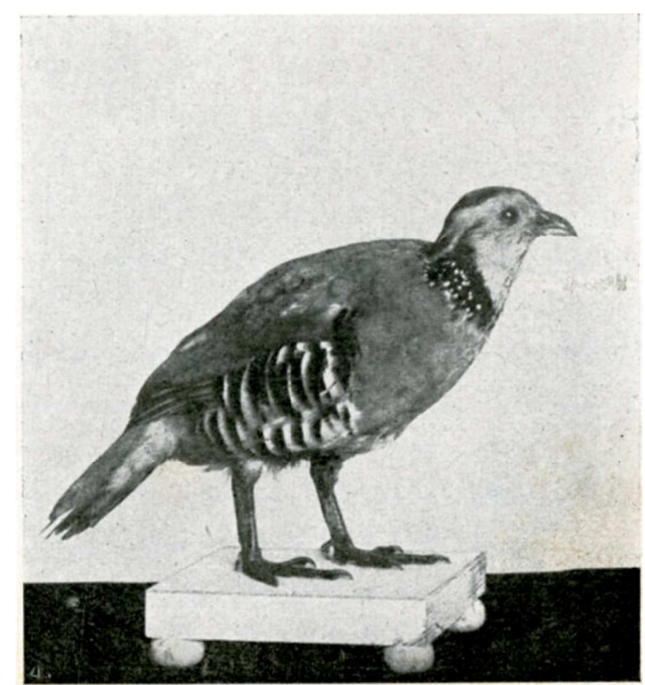

Fig. 1 - Perdiz da Barbaria (Alectoris barbara barbara) da coleção do Rei D. Carlos (Themido, 1944).

Era, pois, esta a bibliografia que Alfred Smith dispunha sobre as aves de Portugal; mas, em Portugal, socorreu-se se outros métodos de pesquisa, desde a observação de campo “...armado com uma espingarda de dois canos e um binóculo - o último, não posso deixar de acrescentar, tão útil para o estudante de ornitologia como a primeira." Além disso, Alfred Smith também frequentou feiras e mercados, de manhã cedo, para inspecionar os "bouquets" de pequenas aves à venda; visitou, ainda, o Museu de Zoologia de Lisboa e o de Coimbra.

Mas Alfred Smith também teve a colaboração de algumas pessoas da comunidade científica, como o já referido Professor Barbosa du Bocage e o Dr. George Suche (ou Such) médico em Londres e coletor no Brasil, onde estava em 1825 e enviou, entre outras coisas, um tucano- 
de-bico-verde (Ramphastos dicoloris) e um tucano-de-cinta ou araçari-de-bico-branco (Pteroglossus aracari) para Nicholas Aylward Vigors (1785-1840) um zoólogo e político irlandês (Macgregor e Headon, 2000). Tal como Alfred Smith, Vigors era "Fellow of the Linnean Society."

Smith recolheu em Portugal uma "pequena" coleção de aves que embalsamou e, já em Inglaterra, recorreu ao conhecido ornitologista inglês Canon Henry Baker Tristram (18221906) (Baker, 1996) para a sua clara identificação.

No artigo que publicou na revista Ibis, em 1868, Alfred Smith enumera 193 espécies e acrescenta: "Também fiz menção acessória de cinquenta e sete outras, que me afirmaram com confiança serem bem conhecidas em Portugal, pessoas em cujo rigor podia confiar." Assim, Smith apresenta uma lista de 250 espécies de aves, elaborada a partir de listas anteriores, mas também com dados novos que recolheu e com comentários próprios.

\subsection{O aditamento do Prof. Bocage à lista de Smith}

Posteriormente o Professor Barbosa du Bocage (1870) fez um revisão à lista de Smith e publicou-a no "Jornal das Sciencias matemáticas, physicas e naturais da Academia Real de Sciencias de Lisboa"; basicamente Barbosa du Bocage fala da reserva que Smith teve sobre a classificação de uma águia-imperial (Aquila heliaca) existente no Museu de Lisboa, e demonstra que é mesmo uma águia-imperial juvenil, espécie que segundo Barbosa du Bocage “...póde dizer-se comum; abunda nas serras da Beira e do Alemtejo. D'esta ultima província tenho recebido mais d'uma vez exemplares vivos d'ella."

Acrescenta, depois, uma listagem de 44 espécies de aves de Portugal não referidas por Smith, e começa com a Aquila naevia, cujo nome atual é Aquila clanga, referindo "Um exemplar proveniente de Traz-os-montes, morto nos arredores de Bragança." A Aquila clanga é atualmente muito rara em Portugal, havendo apenas 9 observações registadas desde 1998, todas no estuário do Tejo, salvo uma, no estuário do Sado 5 .

Refere, em seguida, a Alauda lusitana Gm. (Fig. 2) dizendo que "Não existem ainda exemplares d'esta espécie no museu de Lisboa, porém sei que se encontra frequentemente

\footnotetext{
${ }^{5}$ Fonte: http://avesdeportugal.info/, acedido em 04/08/2013.
} 
no Alentejo e Algarve; d'esta província trouxe vários exemplares d'ela um ornitologista de Halle, o sr. E. Rey, que ali foi recentemente." Barbosa du Bocage referia-se a Eugène Rey (1838-1909), ornitologista alemão que visitara Portugal no ano anterior (1869) e deu conta das suas observações no artigo "Zur Ornis von Portugal" (TA: Para a Ornitologia de Portugal) publicado no "Journal für Ornithologie" (Rey, 1872).

Na reedição da "Histoire Naturelle", do Conde de Buffon ${ }^{6}$, da autoria de Charles Sonnini", feita em 1800-1801, este autor acrescentou uma nota intitulada "L'Alouette de Portugal" na qual, depois de descrever a espécie, diz que "É ainda ao Senhor Latham que devemos o conhecimento desta espécie de cotovia, natural de Portugal" John Latham ${ }^{8}$ escreveu a "General History of Birds" (1822) e fala da "Portugal Lark" de que faz uma pequena descrição que começa com a indicação de ter um "bico robusto" e termina dizendo que "habita Portugal", informação que atribui ao "senhor Pennant"9.

Em 1810 Antero Seabra ${ }^{10}$, no seu "Catalogue des Vertébrés du Portugal" considera a Alauda deserti (Licht) (Oliv. 18), sinónimo de Alauda lusitanica Blyth (Oliv. 18), e da Ammomanes deserti (Oliv. 18) e escreve que "Hab. Env. de Coimbra (Oliv. 18)".

Em 1816 o "Nouveau dictionnaire d' histoire naturelle" registava:

A Cotovia de Portugal, Alauda lusitana, Lath. A côr geral da plumagem desta cotovia é um ruivo muito pálido, que fica ainda mais claro nas partes inferiores; as coberturas e as penas das asas tem uma bordadura cinzenta, e as penas da cauda são ruivas amareladas, mais claras nas penas exteriores; a ponta do bico e as unhas são pretas; o resto do bico é branco, e os pés são cor de carne. Esta ave tem tantas semelhanças com a alouette calandrelle (Alauda arenaria, Vieill,) depois da muda, que eu julgo que pertencem à mesma espécie. (pág. 371, TA).

\footnotetext{
6 Georges-Louis Leclerc, Conde de Buffon (1707-1788) foi um naturalista, matemático, cosmólogo e enciclopedista francês.

${ }^{7}$ Charles-Nicolas-Sigisbert Sonnini de Manoncourt (1751-1812) foi um naturalista francês.

8 John Latham (1740-1837) foi um médico e ornitólogo britânico

${ }^{9}$ Thomas Pennant (1726-1798), um amador de antiguidades e naturalista britânico.

${ }^{10}$ Antero Frederico Seabra (1874-1952, Professor Catedrático e Naturalista do Museu e Laboratório Zoológico da Universidade de Coimbra
} 


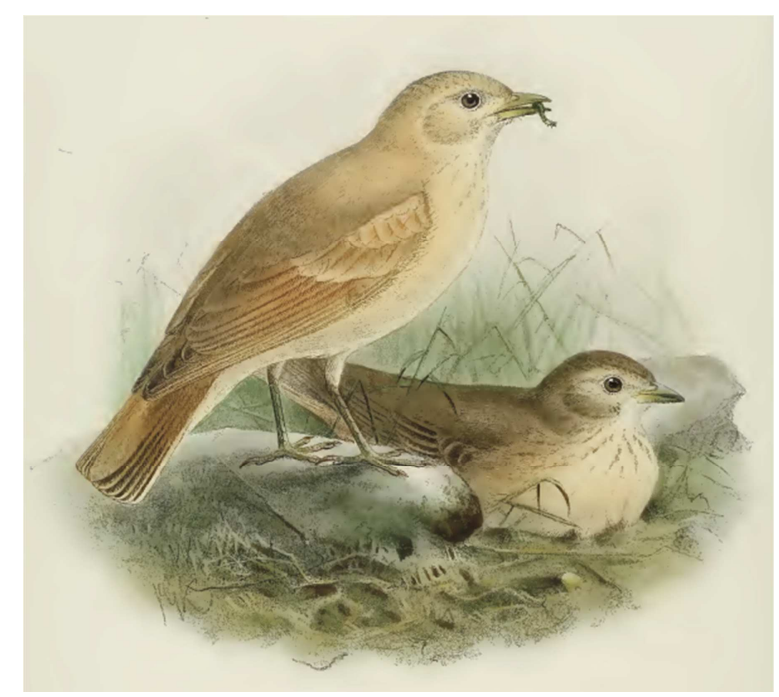

Fig. 2 - Ammomanes deserti, ilustração de Henry Eeles Dresser (1871)

A "Alouette calandrelle" tem o nome atual de Calandrella brachydactyla Leisler, 1814 e é a Calhandrina-comum, que se encontra em todo o território nacional, na primavera e verão, mas que nada tem a ver com a erroneamente chamada "Cotovia de Portugal".

O "Catálogo de las aves de España, Portugal y Islas Baleares" dá como sinónimo da Alauda lusitana $\mathrm{Gm}$ a Alauda deserti Licht e anota "Accidentalmente en Granada (Seoane)" Obetenida dos veces en San Ildefonso (Castellarnau) [Barcelona]" (Prosper, 1886:66).

Entre 1871 e 1882, o ornitologista inglês Henry Eeles Dresser (1838-1915) publica uma extensa história das aves da Europa e refere a Alauda lusitanica, a "Portugal Lark de Latham", considerando que houve um erro de identificação, e que se trata da Ammomanes deserti Licht." ${ }^{12}$, e acrescenta "Nem mesmo parece que qualquer espécime autêntico de A. deserti tenha sido obtido em Portugal ou Espanha." (Dresser, 1871: 329).

Apesar disso, Paulino d'Oliveira13 (1869) publica "Aves da Península Ibérica e especialmente de Portugal" e sobre a Alauda lusitanica faz a seguinte nota:

119 A. lusitanica, Blyth. (A. deserti, Calb.).

Hab. - Ha annos que ferimos uma cotovia perto de Coimbra, e presumimos não poder ser senão um ind. d'esta esp. Para a estudar vagarosamente mettemol-a n'uma passareira e no dia immediato tinha desapparecido. - Cita-se do s. e e. de Hesp. - Afr. (Oliveira, 1896:139)

\footnotetext{
${ }^{11}$ Víctor López Seoane y Pardo-Montenegro (1832-1900) foi um naturalista galego.

${ }^{12}$ Martin Hinrich Carl Lichtenstein (1780-1857), zoólogo alemão.

${ }^{13}$ Manuel Paulino de Oliveira (1837-1899). Professor da Faculdade de Filosofia da Universidade de Coimbra, Diretor do Museu de História Natural (1888-1889).
} 
Quer William C. Tait, no seu livro "The Birds of Portugal" (Tait, 1924), quer Reis Júnior, no seu "Catálogo Sistemático e Analítico das Aves de Portugal" (Júnior, 1930-1935), quer ainda António Armando Themido, no livro "Aves de Portugal" (Themido, 1952) ignoram a espécie. Atualmente esta espécie distribui-se desde o Sara à Península Arábica, Médio Oriente, Irão, Afeganistão e Paquistão, pelo que tudo indica que Henry Dresser, em 1871, tinha razão e a espécie nunca existiu em Portugal.

\section{Conclusões}

O rev. Alfred Charles Smith (1868) foi, porventura, o primeiro turista (ecoturista) que visitou Portugal motivado pela ornitologia.

Embora outros estrangeiros tivessem estado antes em Portugal, com interesses naturalistas, mas por razões de negócios, Smith é o primeiro a assumir-se como turista, e a terminar o seu livro "Narrrative of a spring tour in" Portugal do seguinte modo:

E, como última palavra, deixem-me cordialmente recomendar, não só a turistas em geral, mas especialmente aos meus irmãos Ornitologistas, uma viagem a este canto do extremo sudoeste da Europa, agora tão acessivel, quer por mar como terra, e que oferece tantos e tão variadas atrações - um clima quente e seco para quem busca saúde; permanece incomparavelmente eclesiástico e conventual, de um carácter único, para o eclesiástico ou o arquiteto; belo cenário para o artista; com costumes nobres, no meio de gente agradecida e hospitaleira, para os turistas em geral; enquanto que para $o$ naturalista de cada ramo, o geólogo, o botânico, o entomologista, o zoólogo generalista, há uma rica recolha de factos que devem ser aproveitados neste território que, embora tão perto das nossas costas e, agora, de fácil acesso é, talvez, menos conhecido do público que viaja que qualquer outra região da Europa. (Smith, 1870: 216).

Em 1970, John Gooders publicou em Londres o livro "Where to watch birds in Britain and Europe" e nele sugere uma série de locais a visitar em Portugal para ver aves, desde a lagoa de Albufeira ao Alentejo, da Ria de Aveiro ao Estuário do Tejo. Gooders escreveu, a propósito da Ria de Aveiro:

A Pousada da Ria está situada nesta ponta de areia, e todos os quartos tem um terraço sobre a laguna e, assim, você pode combinar ornitologia com o seu chá (café?) matinal. (Gooders, 1970)

Esta localização priviligiada, a quantidade enorme de (eco)turistas que, ao longo de décadas optaram pela Pousada da Ria por causa do livro do John Gooders e, obviamente, por causa da sua localização, demoraram anos a perceber; só muito recentemente a temática da 
ornitologia foi introduzida na pousada, através de um painel decorativo do bar, mas sem outro incentivo, como listas de espécies observáveis, melhores locais de observação, percursos guiados, etc.

Em 1973, Oleg Polunin e B.E. Smythies publicam em Oxford o livro "Flowers of South-West Europe - A Field Guid" que, pela primeira vez, indica itinerários e locais de observação de plantas em Portugal e dá interessantes e importantes informações sobre as espécies que podem ser observadas. Curiosa a referência feita, no capítulo sobre o Algarve, a um país bucólico que, entretanto, se perdeu:

Quem circule pelas estradas do Algarve não pode ficar indiferente ao trabalho de quem as mantém, os cantoneiros do Ministério das Obras Públicas, nem ao aspecto limpo e bem arranjado das suas margens, plantadas de todas as cores com acácias ornamentais, marmeleiros de grandes flores brancas $e$ ligeiramente rosadas em Março e Abril, lírios (principalmente Iris albicans com alguns I. Germânica), Salvia officinalis, geránios e outras flores. (Polunin \& Smythies, 1973).

Também esta obra motivou a vinda a Portugal de muitos turistas (ecoturistas) em busca da flora mediterrânica.

Nos tempos mais recentes a designação "ecoturismo" implantou-se em Portugal e surgiram algumas empresas de ecoturismo, embora a confusão com outras formas de turismo na natureza (muito predador) seja, ainda, grande.

O potencial de Portugal para o ecoturismo é muito relativo, quando comparado com os grandes destinos ecoturísticos africanos e americanos, e reside no facto do país conter elementos da paisagem atlântica e da paisagem mediterrânica, ter um interior relativamente preservado e de possuir uma série de endemismos de fauna e de flora; acresce a isto o clima ameno, a segurança e os custos moderados de estadia.

Temos, no entanto, alguns pontos fracos: a enorme falta de informação sobre os sítios a visitar, a má sinalização rodoviária, a ausência de equipamentos de acolhimento, e a falta de percursos pedestres sinalizados e guias especializados.

A paisagem é, sem sombra de dúvida, a tela de fundo de toda a atividade turística e, muito em especial, da ecoturística. Paisagens naturais e não degradadas são escassas em Portugal, pois todo o território foi profundamente transformado pelo Homem, ao longo dos últimos milénios. A fauna é, assim, um dos maiores atrativos do ecoturista, e muito especialmente as aves. 
Neste particular, Portugal é muito interessante para amadores de ornitologia do Centro e Norte da Europa, que aqui podem ver com facilidade uma série de espécies mediterrânicas, que não chegam aos seus países: o Grifo (Gyps fulvus), o Abutre-do-Egito (Neophron percnopterus), a Águia-imperial-ibérica (Aquila adalberti) a Galinha-sultana (Porphyrio porphyrio), são exemplos entre dezenas de outras espécies.

Sendo grande o potencial de atração de turistas de natureza provenientes do Centro e Norte da Europa, muito falta, contudo, fazer ao nível de promoção deste segmento turístico em crescimento, que poderá ter um impacto significativo na economia das comunidades do interior.

Um adequado ordenamento de território é fundamental para preservar e valorizar o potencial ecoturístico de Portugal e alguns passos foram dados com a criação da áreas protegidas, com os respetivos planos de ordenamento, e com a Rede Natura 2000, uma rede comunitária de proteção da biodiversidade e dos habitats naturais resultante da aplicação das Diretivas no 79/409/CEE (Diretiva Aves) e no 92/43/CEE (Diretiva Habitats).

Apesar destes instrumentos de proteção, a par com a REN (Reserva Ecológica Nacional) e a RAN (Reserva Agrícola Nacional), serem de inclusão obrigatória nos Planos Diretores Municipais e noutros planos de ordenamento do território, a sua importância tem sido mal avaliada e, frequentemente, em lugar de serem vistos como oportunidade, são vistos como entrave a um modelo de crescimento predador da paisagem.

As caraterísticas geográficas de Portugal, propícias a uma variada biodiversidade, devem ser respeitadas se queremos aproveitar o potencial económico dos serviços prestados pela natureza já avaliado, à escala global, em 33 × $10^{12}$ dólares USA (Costanza et al, 1997).

\section{Referências bibliográficas}

ANÓNIMO (1816). Nouveau dictionnaire d'histoire naturelle. Tomo 1, Chez Deterville, Librairie, Paris.

BAKER, R. A., (1996). The Great Gun of Durham - Canon Henry Baker Tristram, F.R.S. (1822-1906). An outline of his life, collections and contribution to natural history. Archives of Natural History, vol. 23 (3):327-341.

BARBOSA DU BOCAGE (1862). Instruções praticas sobre o modo de coligir e remeter productos zoológicos para o Museu de Lisboa. Imprensa Nacional, Lisboa. 
BARBOSA DU BOCAGE (1870). Algumas observações e aditamento ao artigo do sr. A. C. Smith intitulado "A Sketch of the Birds of Portugal" (Ibis, 1968, pag. 428). Jornal das Sciencias Matemáticas, Physicas e Naturais, Academia Real de Sciencias de Lisboa, Tomo II, Agosto 1868 - Dezembro de 1869, 214-219.

BUFFON, Leclerc de (1785). Histoite Naturelle, Generalle et particuliere. Redigé par C. S. Sonnini. Tom. 51, Paris.

COSTANZA et al. (1997) The value of the world's ecosystem services and natural capital. Nature, 387:253-260

DRESSER, H. E. (1871-1881). A History of the Birds of Europe, including all the species inhabiting the Western Paleartic Region. Vol IV, Publicação do autor, Londres.

GOODERS, John (1970). Where to watch birds in Britain and Europe. André Deutsch, Londres.

GONÇALVES, Maria Guilhermina Bessa (2001). Considerações a partir de uma dissertação centrada na comunidade britânica do Porto. Sociologia: revista da Faculdade de Letras do Porto, pp. 163-182.

JÚNIOR, J. A. dos Reis (1931-1935). Catálogo Sistemático e Analítico das Aves de Portugal. Araújo \& Sobrinho, Porto.

LAMY, Alberto Sousa, e RODRIGUES, Augusto (2000). Furadouro uma terra com passado e com futuro. Comissão de melhoramentos do Furadouro, Ovar.

LATHAM, John (1822). Portugal Lark. General History of Birds. Vol. IV, p. 283, Winchester.

LINNÉ, Caroli (1788). Systema Natura. Tom. I, Pars. II

LORENZO, Juan Antonio y MARTí, Ramón (2003). Ficha da perdiz-moruna. Atlas de las aves reproductoras de España. Ministerio de Agricultura, Alimentación y Medio Ambiente, Madrid.

MACGREGOR, Arthur e HEADON, Abigail (2000). Re-inventing the Ashmolean. Natural history and natural theology at Oxford in the 1820s to 1850s. Archives of natural history 27 (3): 369-406, The Society for the History of Natural History

MATEWS, G. F. (1865). Notes on the Azure-winged magpie (Pica cyanea) \& c., The Naturalist, vol I 49:90, Londres.

OLIVEIRA, M. Paulino d' (1896). Aves da Península Ibérica e especialmente de Portugal. Imprensa da Universidade, Coimbra.

POLUNIN, Oleg e SMYTHIES, B. E. (1973). Flowers of south-west Europe, A field guide. Oxford University Press, Oxford, Inglaterra.

PROSPER, Ventura de los Reyes Y (1886). Catálogo de las aves de España, Portugal é islas Baleares. Anales de la Sociedad Española de Historia Natural, Tomo XV, Madrid.

SEABRA, A. F. (1910). Catalogue des Vertébres du Portugal. Bulletin de la Société Portugaise des Sciences Naturelles, Tome IV, Lisboa.

REY, Eugène (1872). Zur Ornis von Portugal. Journal für Ornithologie, March 1872, Volume 20, Issue 2: 140155.

SMITH, A. C. (1868). A Sketch of the Birds of Portugal. íbis, revista da British Ornithologists' Union, Volume: 10, Issue: 4: 428-460, Peterborough, UK.

SMITH, Alfred Charles (1870). Narrative of a spring tour in Portugal. Longmans, Green, and Ca, Londres.

TAIT, William C. (1924). The Birds of Portugal. F. F. \& G. Witherby, Londres.

THEMIDO, António Armando (1944). Sobre a suposta existência em Portugal da perdiz da Barbaria, "Alectoris barbara barbara" (Bonnaterre). Memórias e Estudos do Museu Zoológico da Universidade de Coimbra, 156: 14, Coimbra

THEMIDO, António Armando (1952). Aves de Portugal (Chaves para a sua determinação). Coimbra Editora, Limitada, Coimbra. 